\title{
Analgesic and anti-inflammatory activity of the aqueous extract of Rheedia longifolia Planch \& Triana
}

\author{
Valber da Silva Frutuoso $/{ }^{+} /+$, Márcia Magalhães Monteiro/ ${ }^{++}$, \\ Fábio Coelho Amendoeira, Andressa Luiza Figueiredo Almeida, \\ Diogo Dibo do Nascimento, Ana Luiza Rangel Bérenger*, Maria Auxiliadora Coelho Kaplan*, \\ Maria Raquel Figueiredo*, Patrícia T Bozza, Hugo C Castro-Faria-Neto*
}

Laboratório de Imunofarmacologia, Departamento de Fisiologia e Farmacodinâmica, Instituto Oswaldo Cruz-Fiocruz, Av. Brasil 4365, 21040-900 Rio de Janeiro, RJ, Brasil * Laboratório de Produtos Naturais 3, Farmanguinhos-Fiocruz, Rio de Janeiro, RJ, Brasil

Rheedia longifolia Planch et Triana belongs to the Clusiaceae family. This plant is widely distributed in Brazil, but its chemical and pharmacological properties have not yet been studied. We report here that leaves aqueous extract of R. longifolia (LAE) shows analgesic and anti-inflammatory effects. Oral or intraperitoneal administration of this extract dose-dependently inhibited the abdominal constrictions induced by acetic acid in mice. The analgesic effect and the duration of action were similar to those observed with sodium diclofenac, a classical non-steroidal analgesic. In addition to the effect seen in the abdominal constriction model, LAE was also able to inhibit the hyperalgesia induced by lipopolysaccharide from gram-negative bacteria (LPS) in rats. We also found that $\mathrm{R}$. longifolia LAE inhibited an inflammatory reaction induced by LPS in the pleural cavity of mice. Acute toxicity was evaluated in mice treated with the extract for seven days with $50 \mathrm{mg} / \mathrm{kg} /$ day. Neither death, nor alterations in weight, blood leukocyte counts or hematocrit were noted. Our results suggest that aqueous extract from R. longifolia leaves has analgesic and anti-inflammatory activity with minimal toxicity and are therefore endowed with a potential for pharmacological control of pain and inflammation.

Key words: Rheedia longifolia - analgesic - anti-inflammatory - opioid receptors - natural products

Medicinal plants have been used since ancient times as medicines for the treatment of diseases and still play a key role in world health. The chemical diversity of plants has made them one of the main sources for the isolation of bioactive organic compounds (Basso et al. 2005).

Several members of Clusiaceae family exhibit a wide range of biological activities, including the genus $\mathrm{Hy}$ pericum (Clusiaceae), which comprises approximately 400 species (Robson 1990). This family has led to the isolation of more than 100 compounds, from about 20 different species, with various different biological activities, especially compounds with anti-inflammatory, antimicrobial, antifungal, antiviral, and antidepressant properties (Gustafson et al. 1992, Rocha et al. 1994, Minami et al. 1996, Viana et al. 2003, Suffredini et al. 2006). Rheedia, another genus of Clusiaceae family, is very commonly used in folk medicine for innumerous disorders, including constipation, rheumatism, inflammation, and pain (Côrrea 1984, Bittar et al. 2000). The literature shows that plants of this genus are rich in biflavonoids, benzophenones, flavonoids, xanthones,

Financial support: Faperj, CNPq, Papes. PTB is an International Scholar from Howard Hughes Medical Institute.

${ }^{+}$Corresponding author: frutuoso@ioc.fiocruz.br

${ }^{++}$These authors contributed equally to this report.

Received 31 October 2006

Accepted 15 January 2007 triterpenes, and steroids (Delle Monache et al. 1983, 1984). In this context, Rheedia gardneriana Planch et Triana leaves are also used to treat inflammation, pain, and infections. In fact, biflavonoids with analgesic and anti-inflammatory activities have been isolated from the leaves of this plant (Bittar et al. 2000).

Rheedia longifolia Planch \& Triana is an arboreal plant native of tropical and subtropical Americas is popularly known in Brazil as "bacupari". Considering the antiinflammatory and analgesic effect of plants from the same genus, here, we evaluate the antinociceptive and anti-inflammatory activities of $R$. longifolia using an aqueous extract obtained from the leaves of this plant.

\section{MATERIALS AND METHODS}

Preparation of the extract - Leaves of Rheedia longifolia Planch \& Triana were collected at Botanical Garden, Rio de Janeiro, Brazil, on February 20, 1996. A voucher of this plant was deposited at Rio de Janeiro Botanical Garden Herbarium (RB) under the number 327826. The collected material was reduced to small fragments and dried at $40^{\circ} \mathrm{C}$ in an oven with air circulation. The dried plant material ( $300 \mathrm{~g})$ was added to water at $100^{\circ} \mathrm{C}$ and it was kept infused until the water cooled, constituting the aqueous extract. The extracted was then filtrated and the filtrate lyophilized to obtain the aqueous extract of the leaves of $R$. longifolia $(63.5 \mathrm{~g})$.

Animals - Male Swiss mice and Wistar rats weighing 23-30 and 130-200 g respectively, were used. The animals were obtained from the animal-breeding colony at the Oswaldo Cruz Foundation and maintained in the animal room of the Department of Physiology and Pharma- 
codynamics with free access to pelleted diet and water and a controlled period of light/darkness of 12/12 h.

The experiments in this study received prior approval from the Oswaldo Cruz Foundation's Animal Welfare Committee.

Writhing test - Abdominal constrictions in mice were caused by the intraperitoneal injection of $0.8 \%$ acetic acid. The animals were previously treated, by oral administration (p.o.) or intraperitoneal administration (i.p), with different doses of $R$. longifolia leaves aqueous extract (LAE) $1 \mathrm{~h}$ before the stimulation with acetic acid. Control animals received the same volume of vehicle (saline). Five minutes after the acetic acid injection, the number of times that each animal presented abdominal constriction was counted for 10 consecutive minutes. Morphine $(8 \mathrm{mg} / \mathrm{kg}$, s.c. $)$, sodium diclofenac $(1 \mathrm{mg} / \mathrm{kg}$ i.p.), and morphine antagonist naloxone $(8 \mathrm{mg} / \mathrm{kg}$, i.p.), were used as standard drugs for comparison. The pretreatment was also performed for 1 to $4 \mathrm{~h}$ prior to the acetic acid injection. Each experimental group was performed with at least six animals.

Hyperalgesia test according to Hargreaves - Hyperalgesia was induced by the intraplantar injection of LPS $(250 \mathrm{ng} / \mathrm{paw})$ in the rats left hind paw. The extract $(50 \mathrm{mg} / \mathrm{kg})$ was injected (i.p) $1 \mathrm{~h}$ before stimulation with LPS. The hyperalgesia was evaluated according to the method described by Hargreaves for nociceptive induction (Hargreaves et al. 1988, Costello \& Hargreaves 1989). The intensity of the hyperalgesia was quantified as the variation of the time of reaction (index of hyperalgesia, $\mathrm{IH})$ obtained by the equation: $\mathrm{IH}=(\mathrm{T} 0 / \mathrm{Tn})-1$, where $\mathrm{T} 0$ is the time of reaction before the injection of the stimulus, while $\mathrm{Tn}$ is the value measured at different time points after the stimulus. In the present work, the analysis of the reaction was performed 2 and $6 \mathrm{~h}$ after the administration of the LPS. Control animals received the same volume of vehicle. Each experimental group was performed with at least six animals.

Tail flick test - The nociceptive response was evaluated by recording the latency to withdrawal of the tail in response to a specific intensity of noxious skin heating, as previously described by Ohsawa and Kamei (1999). The tails of mice were exposed to a focused beam of light from a $45-\mathrm{W}$ projection bulb. When a withdrawal response occurred, the stimulus was terminated and the latency of the response was measured electronically. In the absence of a response after $10 \mathrm{~s}$ the trial was terminated to prevent tissue damage. Changes in withdrawal response latency induced by the aqueous extract from R. longifolia leaves $(10 \mathrm{mg} / \mathrm{kg}, \mathrm{i}$. p.) or sodium diclofenac $(10 \mathrm{mg} / \mathrm{kg}$, p.o.) were evaluated 30,60 , and $90 \mathrm{~min}$ after treatment. Each experimental group was performed with at least eight animals.

Evaluation of the anti-inflammatory activity - Pleurisy was induced by an intrathoracic injection of LPS $(250 \mathrm{ng} /$ cavity) in mice. The leaves aqueous extract of R. longifolia $(50 \mathrm{mg} / \mathrm{kg}$, i.p.) was administered $1 \mathrm{~h}$ before the injection of LPS. Six hours after the injection of LPS the animals were sacrificed in a $\mathrm{CO}_{2}$ chamber, the thoracic cavity was opened and washed with $1 \mathrm{ml}$ of PBS containing heparin 20 UI. The pleural wash was collected with the aid of a pipette and used to analyze the cellular infiltrate (total and differential leukocyte counts). The total number of leukocytes collected in pleural wash was evaluated in a Neubauer chamber after dilution of a pleural wash sample in $2 \%$ acetic acid. The differential analysis of leukocytes was accomplished in cytosmears stained with May-Grunwald-Giemsa dye. Each experimental group was performed with at least eight animals.

Toxicology studies - The leaves aqueous extract of $R$. longifolia $(50 \mathrm{mg} / \mathrm{kg}$, i.p., once a day) was administered to mice for seven consecutive days for evaluation of the potential acute and sub-acute toxicity. The parameters observed in this period were: death of the animals, weight variation, and hematocrit and blood leukocyte counts. Twenty-four hours after the seventh injection of $\mathrm{LAE}$, the animals were sacrificed in a $\mathrm{CO}_{2}$ chamber, the peritoneal cavity was opened and washed with $3 \mathrm{ml}$ of PBS containing heparin (20 UI). Peritoneal wash was collected and used for analysis of the cellular infiltrate as described above. Each experimental group was performed with at least ten animals.

Statistical analysis - The data were represented as mean \pm standard error of mean (SEM). The statistical analysis involving two groups was done using Student's test T. ANOVA followed by Student Neuman-Keuls test was used to compare three or more groups. The results were considered significant for values of $p \leq 0.05$ (GraphPad Instat version 3.05, 2000 - GraphPad Software Inc).

\section{RESULTS}

The $R$. longifolia LAE has potent analgesic activity. LAE was administered orally (p.o.) to mice in doses of $10 \mathrm{mg} / \mathrm{kg}, 25 \mathrm{mg} / \mathrm{kg}, 50 \mathrm{mg} / \mathrm{kg}$, and $100 \mathrm{mg} / \mathrm{kg} 1 \mathrm{~h}$ before acetic acid injection (0.8\%; i.p.). Fig. 1A shows that doses of $25 \mathrm{mg} / \mathrm{kg}$ and $50 \mathrm{mg} / \mathrm{kg}$ significantly decreased the number of abdominal constrictions induced by acetic acid in 44.8 and $63.5 \%$, respectively. The dose of $10 \mathrm{mg} / \mathrm{kg}$ failed to decrease the number of abdominal constrictions induced by acetic acid. The dose of 100 $\mathrm{mg} / \mathrm{kg}$ was as effective as the dose of $50 \mathrm{mg} / \mathrm{kg}$. As shown in Fig. 1B, the administration of LAE through intraperitoneal route in doses ranging from $0.01-1 \mathrm{mg} / \mathrm{kg}$, produced a more potent and efficient inhibitory effect in the abdominal constriction test than the one obtained when the extract was administered orally. The percentages of inhibition observed in this case were 22.7, 52.3, and $65.4 \%$ for $0.01 \mathrm{mg} / \mathrm{kg}, 0.1 \mathrm{mg} / \mathrm{kg}$, and $1 \mathrm{mg} / \mathrm{kg}$, respectively.

The analgesic effect of $R$. longifolia LAE was confirmed using the Hargreaves model of hyperalgesia. In this experimental assay, we observed that the intraperitoneal injection of LAE, at $50 \mathrm{mg} / \mathrm{kg}, 1 \mathrm{~h}$ before the stimulation with LPS completely inhibited hyperalgesia at $2 \mathrm{~h}$ and was still effective ( $45 \%$ of inhibition) at $6 \mathrm{~h}$ as demonstrated by a decrease in the difference of the latency time of response (Fig. 2). 

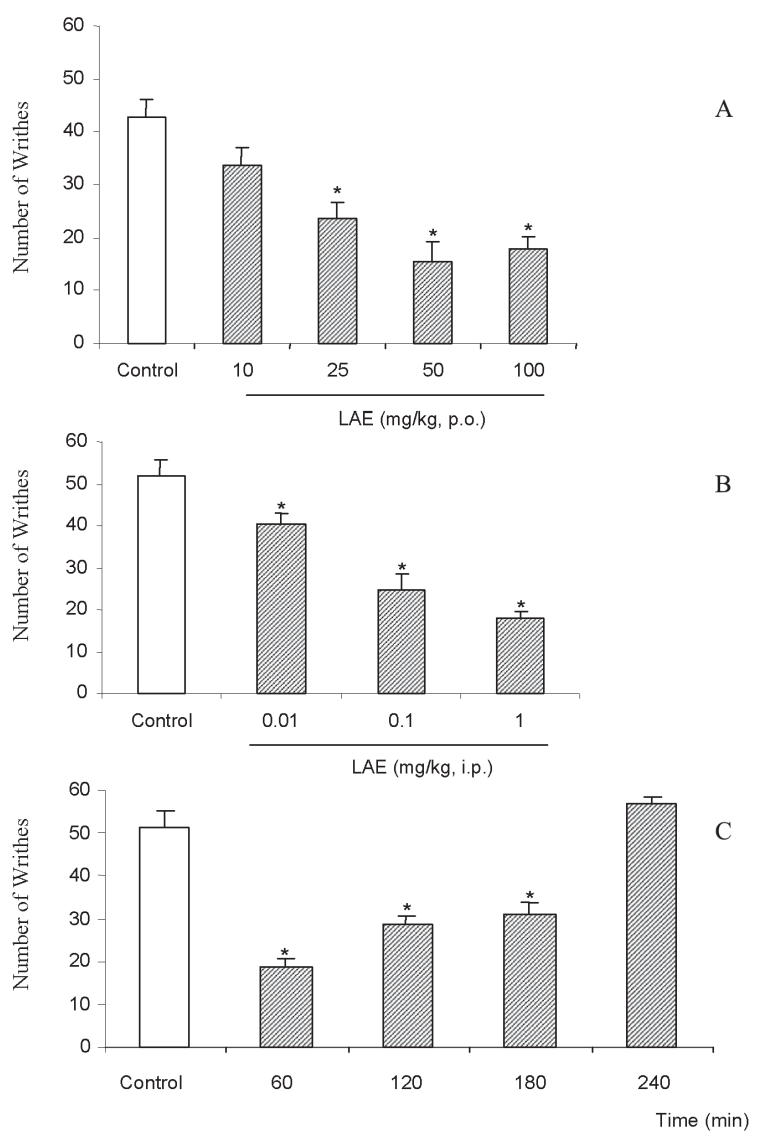

Fig. 1: dose-response curve (A and B) and time-response curve (C) for the analgesic effect of Rheedia longifolia leaves extract (LAE) on acetic acid-induced abdominal constrictions in mice. Abdominal constrictions were counted over a 10 min period following i.p. injection of acetic acid. R. longifolia LAE was administered p.o. (A) or i.p (B and C) $1 \mathrm{~h}$ (A and B) or $1,2,3$, and $4 \mathrm{~h}(\mathrm{C})$ before acetic acid injection $(0.8 \%)$. Control animals received an i.p. injection of the vehicle. Each bar is the mean \pm s.e.m. from at least six animals, ${ }^{*} \mathrm{P}<0.05$ (ANOVA Student's Newman Keuls multiple comparisons test).

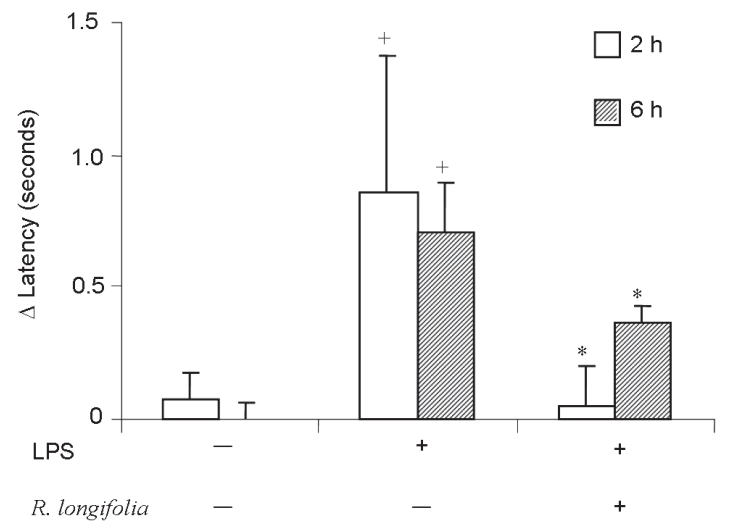

Fig. 2: Rheedia longifolia leaves extract inhibits lipopolysaccharide-induced hyperalgesia in rats. $R$. longifolia (LAE, $50 \mathrm{mg} / \mathrm{kg}$ ) was administered i.p. $1 \mathrm{~h}$ before LPS ( $250 \mathrm{ng} / \mathrm{paw}$ ) injection. Results show the latency time for hind paw withdrawn after heating at 2 and $6 \mathrm{~h}$ after LPS intraplantar injection. Each bar is the mean \pm s.e.m. from at least six animals, $* \mathrm{P}<0.05$ when compared to control and ${ }^{+} \mathrm{P}<0.05$ when compared to LPS- $/ R$. longifolia LAE group (ANOVA Student's Newman Keuls multiple comparisons test).
To establish a standard for comparison between the LAE and classical analgesics, we treated mice with sodium diclofenac or with the opioid morphine. Morphine $(8 \mathrm{mg} / \mathrm{kg}$, s.c. $)$ abolished abdominal contortions induced by acetic acid. As expected, the analgesic effect of morphine was antagonized, in animals that received naloxone $(8 \mathrm{mg} / \mathrm{kg}$, i.p.), an opioid receptor antagonist, 30 min before morphine administration. Interestingly, naloxone administration $30 \mathrm{~min}$ before LAE significantly antagonized the analgesic effect shown by the extract (Fig. $3 \mathrm{~A}$ ) or by sodium diclofenac in this model (Fig. 3B). To confirm the involvement of central nervous system in the antinociceptive effect of LAE, we use the tail flick test to differentiate the central and peripheral mechanisms of nociception. Our results show that neither LAE nor diclofenac were able to modify the reaction time in the tail flick test (Fig. 4). It is important to note that in these experiments we used doses of LAE that were 10 times higher than the doses used in previous experiments.

We also evaluated the duration of the analgesic effect of the LAE in the acetic acid-induced abdominal constriction model. In this case, four different groups
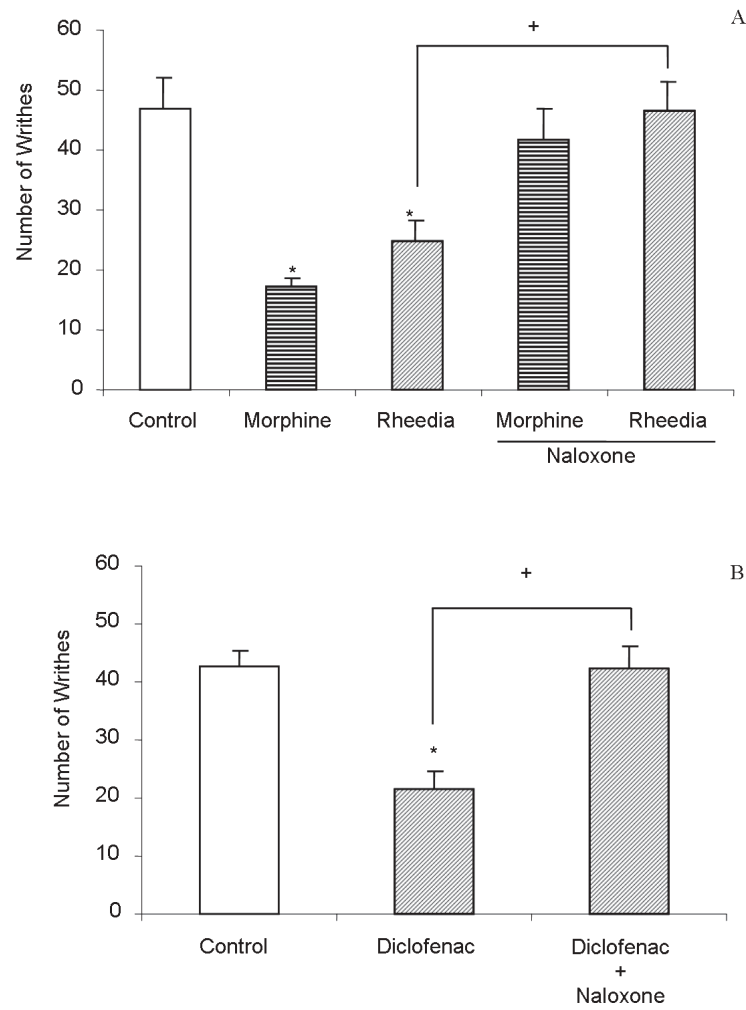

Fig. 3: naloxone inhibits morphine Rheedia longifolia leaves extract (A) and diclofenac (B) induced analgesic effect in acetic acid-induced abdominal constrictions model. Abdominal constrictions were counted over a $10 \mathrm{~min}$ period following i.p. acetic acid injection. Naloxone $(8 \mathrm{mg} / \mathrm{kg}$, i.p.) was injected $30 \mathrm{~min}$ before injection of morphine $(8 \mathrm{mg} / \mathrm{kg}$, s.c.), $R$. longifolia leaves extract ( $1 \mathrm{mg} / \mathrm{kg}$ i.p.) or diclofenac $(1 \mathrm{mg} / \mathrm{kg}$ i.p.). Treatments were administered $1 \mathrm{~h}$ before acetic acid injection. Each bar is the mean \pm s.e.m. from at least six animals, ${ }^{*} \mathrm{P}<0.05$ when compared to control and ${ }^{+} \mathrm{P}<0.05$ when compared to naloxone treated animals (ANOVA Student's Newman Keuls multiple comparisons test). 


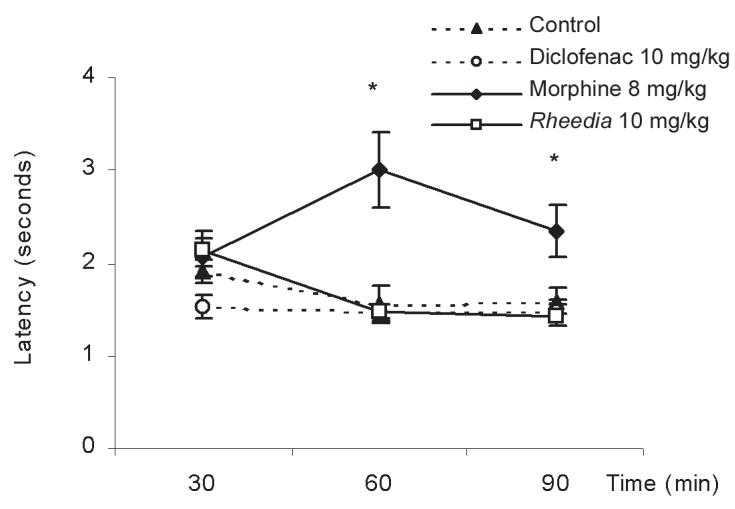

Fig. 4: Rheedia longifolia leaves extract (LAE) and diclofenac do not affect reaction time in tail flick test. $R$. longifolia LAE and diclofenac were administered i.p. $1 \mathrm{~h}$ before thermal stimulation $(45 \mathrm{~W})$. Each point is the mean \pm s.e.m. from at least eight animals, ${ }^{*} \mathrm{P}<0.05$ (ANOVA Student's Newman Keuls multiple comparisons test).

of mice were pre-treated with $\operatorname{LAE}(1 \mathrm{mg} / \mathrm{kg}$, i.p. $)$ at 1 , 2, 3 or $4 \mathrm{~h}$ before acetic acid injection. As shown in Fig. 1C, LAE has a short lasted effect that was over after a period of $3 \mathrm{~h}$.

R. longifolia LAE inhibits inflammation - Six hours after the intrathoracic administration of LPS an increase in total leukocyte numbers was observed in the pleural wash recovered from LPS-injected mice (Penido et al. 1997). This leukocyte accumulation was characterized by a marked accumulation of neutrophils (Fig. 5).

R. longifolia LAE is well tolerated by the animals To test for potential toxic effects of $R$. longifolia, we treated mice for seven consecutive days with $50 \mathrm{mg} / \mathrm{kg}$ of the LAE by i.p. route. We recorded death events in the group, as well as alterations in the weight gain, hematocrit, and blood leukocyte counts during the extract administration until $24 \mathrm{~h}$ after the last injection. No deaths were observed in the animals receiving LAE for seven days. Moreover, there were no significant changes in weight gain, hematocrit (data not shown) and blood leukocyte counts (Table) when comparing the group receiving the extract with the control group receiving the same volume of vehicle. Twenty-four hours after the last intraperitoneal injection of LAE the animals were sacrificed and a peritoneal lavage was performed to investigate if the administration of the extract would have local irritating effect. No alterations in the peritoneal population of resident leukocytes were noted in animals injected with LAE as compared to animals receiving vehicle (data not shown).

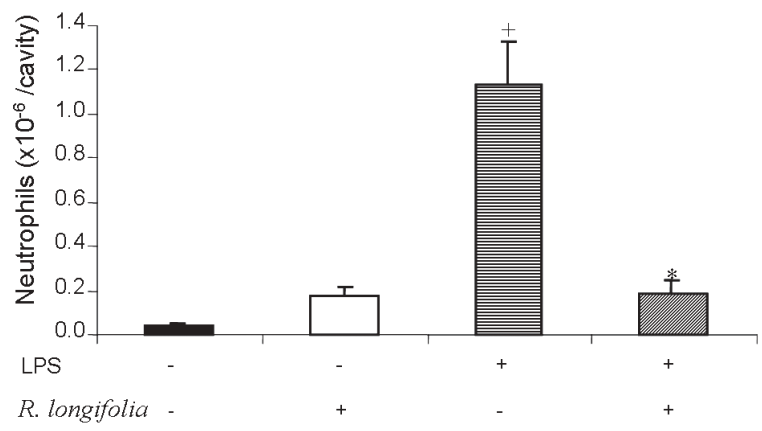

Fig. 5: Rheedia longifolia leaves extract inhibits lipopolysaccharide-induced neutrophil accumulation in the mice pleural cavity. Neutrophil counts were performed in the pleural wash $6 \mathrm{~h}$ after i.t. injection of LPS. $R$. longifolia leaves extract $(50 \mathrm{mg} / \mathrm{kg})$ were administered i.p. $1 \mathrm{~h}$ before LPS ( $250 \mathrm{ng} /$ cavity) injection. Each bar is the mean \pm s.e.m. from at least eight animals, ${ }^{*} \mathrm{P}<0.05$ when compared to control and ${ }^{+} \mathrm{P}<0.05$ when compared to saline treated animals (ANOVA Student's Newman Keuls multiple comparisons test).

TABLE

Seven days treatment with Rheedia longifolia leaves (LAE) extract does not affect blood leukocyte counts in mice

\begin{tabular}{|c|c|c|c|c|c|}
\hline \multirow[t]{2}{*}{ Treatment } & \multirow[t]{2}{*}{$\mathrm{n}$} & \multicolumn{4}{|c|}{ Leukocytes $\left(\mathrm{x} 10^{6} / \mathrm{ml}\right)$} \\
\hline & & Day 1 & Day 3 & Day 5 & Day 8 \\
\hline & & \multicolumn{4}{|c|}{ Total blood leukocytes } \\
\hline Saline & 10 & $14.23+2.58$ & $13.99+1.22$ & $10.9+0.88$ & $10.81+1.13$ \\
\hline \multirow[t]{2}{*}{$\mathrm{LAE}(50 \mathrm{mg} / \mathrm{kg})$} & 10 & $10.76+0.73$ & $12.38+1.65$ & $10.67+1.68$ & $10+0.9$ \\
\hline & & \multicolumn{4}{|c|}{ Blood mononuclear cells } \\
\hline Saline & 10 & $11.96+2.3$ & $11.7+1.08$ & $8.96+0.79$ & $8.76+0.87$ \\
\hline \multirow[t]{2}{*}{$\operatorname{LAE}(50 \mathrm{mg} / \mathrm{kg})$} & 10 & $9.28+0.7$ & $10.68+1.52$ & $7.89+1.31$ & $7.68+0.82$ \\
\hline & & \multicolumn{4}{|c|}{ Blood neutrophils } \\
\hline Saline & 10 & $2.23+0.34$ & $2.31+0.42$ & $1.76+0.19$ & $1.83+0.32$ \\
\hline \multirow[t]{2}{*}{$\mathrm{LAE}(50 \mathrm{mg} / \mathrm{kg})$} & 10 & $1.47+0.19$ & $1.7+0.25$ & $2.34+0.44$ & $2.1+0.18$ \\
\hline & & \multicolumn{4}{|c|}{ Blood eosinophils } \\
\hline Saline & 10 & $0.05+0.05$ & $0+0$ & $0.2+0.08$ & $0.22+0.11$ \\
\hline LAE (50 mg/kg) & 10 & $0+0$ & $0+0$ & $0.47+0.17$ & $0.22+0.12$ \\
\hline
\end{tabular}

Data show the variations in blood leukocyte counts after seven days of $R$. longifolia LAE $(50 \mathrm{mg} / \mathrm{kg})$ or saline solution i.p. daily treatment. 


\section{DISCUSSION}

From an ethno-pharmacological point of view, previous studies indicate the presence of analgesic activity in different species of Rheedia. Recently it was demonstrated that the ethyl acetate extract of $R$. gardneriana has analgesic and anti-inflammatory activity. $R$. gardneriana is used in folk medicine to treat several pathologies, especially inflammation, pain, and infections (Bittar et al. 2000). Interestingly, biflavonoids with analgesic effect were isolated from leaves of $R$. gardneriana (Cechinel Filho et al. 2000). Based on preliminary screening studies showing that the LAE was able to decrease pain in the acetic acid-induced contortion test, we decided to further investigate the analgesic activity of this extract. We demonstrated that the LAE is active either by oral route or by i.p. route although the i.p. route showed a more potent effect. This difference may be attributed to decreased absorption in the gastrointestinal tract as compared to the peritoneal cavity and/or a first pass effect; assuming that the active substance in the LAE may be metabolic inactivated by the liver.

In the present work, we have demonstrated that LAE is equally efficient to sodium diclofenac in inhibiting acetic acid-induced contortions. Considering the fact that LAE has also the ability to inhibit hyperalgesia induced by LPS, an action also shared by acetyl salicylic acid, we may suggest that both agents have a common pharmacological analgesic mechanism of action, (i.e., the inhibition of cyclooxygenase and consequent impairment in prostanoid production). In fact, $\mathrm{PGE}_{2}$ is known to be one of the main mediators of hyperalgesia and inhibitors of prostaglandin synthesis are remarkably efficient in inhibiting this phenomenon (Vane 1971, Meade et al. 1993, Aslanian et al. 1994). Hyperalgesia is frequently detected in association with inflammation and is referred to as "inflammatory pain" (Wall \& Melzack 1994). This phenomenon is thought to be the result of the release of chemical inflammatory mediators such as prostaglandins and cytokines that act regulating the sensibility of the nociceptor fibers (Besson 1997, Ferreira et al. 2000). It is important to note that naloxone was able to interfere with the analgesic effect of LAE, indicating that this extract, is acting through the activation of opioid receptors in the central nervous system. A classical and accurate model to differentiate the central or peripheral mechanisms of nociception is the tail flick test. Our results demonstrate that LAE was not able to modify reaction time in tail flick test even in high doses, showing a similar profile to several NSAIDs which potently antagonize nociception in the writhing test but do not show activity in the tail flick test. Interestingly, naloxone was shown to reverse the effect of sodium diclofenac (Bjorkman 1995), as well as LAE effect. This suggests that the response to NSAIDs is influenced by a secondary interaction with the opioid system. The literature shows that after systemic treatment with diclofenac, increased levels of $\beta$-endorphin have been found central nervous system (Sacerdote et al. 1985). Thus, diclofenac may release $\beta$-endorphin and possibly other classes of endogenous opioids (Bjorkman 1995). In antinociceptive tests, PCPA, a tryptophan hydroxylase inhibitor was used to significant reduce central nervous system 5-HT content. PCPA pretreatment profoundly antagonized the antinociceptive effect of diclofenac. Moreover, s.c. administration of diclofenac reduced both brain-stem and spinal cord content of 5-HT, indicating an increased release of 5-HT in these regions after diclofenac (Bjorkman 1995). These findings provide further evidence for a direct relationship between central 5-HT mechanisms and the antinociceptive effect of diclofenac and indicate that this may involve mechanisms mediated via 5-HT receptors. Moreover, the antinociceptive effect of the NSAIDs studied includes a central component, related to NMDA receptor-induced activation of the NO-system (Bjorkman 1995). These data may in part help to explain the antinociceptive mechanism of LAE.

Nevertheless, since LAE is an unpurified extract one must keep in mind that different bioactive substances may be exerting the analgesic and the anti-inflammatory effects attributed to LAE. New experiments using purified fractions of LAE would be necessary to clarify this point.

Because of the potential use of LAE as a phytotherapeutic to control pain and inflammation it was our interest to verify the possible presence of toxicity after the repeated administration of this extract to animals. We observed that the administration of LAE for seven days did not show any signs of toxicity as evaluated for occurrence of death, changes in blood leukocyte population and body weight gain. Importantly, LAE showed also no signs of causing irritation to the local of administration indicating that this extract is well tolerated when given to animals. Other studies including histology and functional studies of liver, gastrointestinal tract and kidneys are on their way to confirm the low toxicity of LAE.

In summary, our results suggest that aqueous extract of $R$. longifolia leaves has a potent analgesic and antiinflammatory activity and low toxicity. This extract or its isolated chemical components could represent a new resource for the development of new plant-based therapy useful in the control of pain and inflammation.

\section{ACKNOWLEDGEMENTS}

To the Botanical Garden of Rio de Janeiro for the liberation for collection of leaves of Rheedia longifolia used for the preparation of the extract.

\section{REFERENCES}

Aslanian R, Canuthers NI, Kaminski JJ 1994. Cyclooxigenase 2: a novel target for therapeutic intervention. Expert Opin Invest Drugs 3: 1323-1325.

Basso LA, da Silva LH, Fett-Neto AG, de Azevedo Jr. WF, Moreira Ide S, Palma MS, Calixto JB, Astolfi Filho S, dos Santos RR, Soares MB, Santos DS 2005. The use of biodiversity as source of new chemical entities against defined molecular targets for treatment of malaria, tuberculosis, and T-cell mediated diseases - A Review. Mem Inst Oswaldo Cruz 100: 475-506.

Besson JM 1997. The complexity of physiopharmacologic aspects of pain. Drugs 53 (Suppl. 2): 1-9. 
Bittar M, de Souza MM, Yunes RA, Lento R, Delle Monache F, Cechinel Filho V 2000. Antinociceptive activity of I3,II8binaringenin, a biflavonoid present in plants of the guttiferae. Planta Med 66: 84-86.

Bjorkman R 1995. Central antinociceptive effects of non-steroidal anti-inflammatory drugs and paracetamol. Experimental studies in the rat. Acta Anaesthesiol Scand (Suppl.) 103: 144.

Cechinel Filho V, da Silva KL, de Souza MM, Oliveira AE, Yunes RA, Guimaraes CL, Verdi LG, Simionatto EL, Delle Monache F 2000. I3-naringenin-II8 - 4'OMe-eriodictyol: a new potential analgesic agent isolated from Rheedia gardneriana leaves. Z Naturforsch 55: 820-823.

Côrrea MP 1984. Dicionário das Plantas Úteis do Brasil e das Exóticas Cultivadas, Ministério da Agricultura, Instituto Brasileiro de Desenvolvimento Florestal, p. 318-337.

Costello AH, Hargreaves KM 1989. Suppression of carrageenaninduced hyperalgesia, hyperthermia and edema by a bradykinin antagonist. Eur J Pharmacol 171: 259-263.

Delle Monache G, Delle Monache F, Marini-Bettolo GB, Alves de Lima R 1983. Chemical investigation of the genus Rheedia I Prenylated xanthones from Rheedia gardneriana. J Nat Prod 46: 655.

Delle Monache G, Delle Monache F, Waterman PG, Crichton EG, Alves de Lima R 1984. Minor Xanthones from Rheedia gardneriana. Phytochemistry 23: 1757-1759.

Ferreira J, Floriani AE, Filho VC, Delle Monache F, Yunes RA, Calixto JB, Santos AR 2000. Antinociceptive properties of the methanolic extract and two triterpenes isolated from Epidendrum mosenii stems (Orchidaceae). Life Sci 66: 791802.

Gustafson KR, Munro MHG, Fuller RW, Cardellina JH, 1992. The Guttiferones, HIV-inhibitory benzophenones from Symphonia globulifera, Garcinia livingstonei, $G$. ovalifolia and Clusia rosea. Tetrahedron 48: 10093-10102.

Hargreaves K, Dubner R, Brown F, Flores C, Joris J 1988. A new and sensitive method for measuring thermal nociception in cutaneous hyperalgesia. Pain 32: 77-88.
Meade EA, Smith WL, DeWitt DL 1993. Differential inhibition of prostaglandin endoperoxide synthase (cyclooxygenase) isozymes by aspirin and other non-steroidal anti-inflammatory drugs. J Biol Chem 268: 6610-6614.

Minami H, Takahashi E, Kodama M, Fukuyama Y 1996. Three xanthones from Garcinia subelliptica. Phytochemistry 41: 629-633.

Ohsawa M, Kamei J 1999. Possible involvement of spinal protein kinase $\mathrm{C}$ in thermal allodynia and hyperalgesia in diabetic mice. Eur J Pharmacol 372: 221-228.

Penido C, Castro-Faria-Neto HC, Larangeira AP, Rosas EC, Ribeiro-dos-Santos R, Bozza PT, Henriques MG 1997. The role of gammadelta T lymphocytes in lipopolysaccharideinduced eosinophil accumulation into the mouse pleural cavity. J Immunol 159: 853-860.

Robson N 1990. Studies in the genus Hypericum L. (Guttiferae). Trigynobrathys: 1-151.

Rocha L, Marston A, Kaplan MA, Stoeckli-Evans H, Thull U, Testa B, Hostettmann K 1994. An antifungal gamma-pyrone and xanthones with monoamine oxidase inhibitory activity from Hypericum brasiliense. Phytochemistry 36: 1381-1385.

Sacerdote P, Monza G, Mantegazza P, Panerai AE 1985. Diclofenac and pirprofen modify pituitary and hypothalamic betaendorphin concentrations. Pharmacol Res Commun 17: 679684.

Suffredini IB, Paciencia ML, Nepomuceno DC, Younes RN, Varella AD 2006. Antibacterial and cytotoxic activity of Brazilian plant extracts - Clusiaceae. Mem Inst Oswaldo Cruz 101: 287-290.

Vane JR 1971. Inhibition of prostaglandin synthesis as a mechanism of action for aspirin-like drugs. Nat New Biol 231: 232235.

Viana AF, Heckler AP, Fenner R, Rates SM 2003. Antinociceptive activity of Hypericum caprifoliatum and Hypericum polyanthemum (Guttiferae). Braz J Med Biol Res 36: 631634.

Wall PD, Melzack R 1994. Textbook of Pain, Churchill Livingstone, Edinburgh. 